\title{
Integrated assessment of carbon capture and storage (CCS) in the German power sector and comparison with the deployment of renewable energies
}

Originally published as:

Peter Viebahn, Daniel Vallentin, Samuel Höller (2012):

Integrated assessment of carbon capture and storage (CCS) in the German power sector and comparison with the deployment of renewable energies In: Applied Energy 97 (2012) 238-248 
Peter Viebahn ${ }^{a,{ }^{*}}$, Daniel Vallentin ${ }^{a}$, Samuel Höller ${ }^{a}$

\section{Integrated assessment of carbon capture and storage (CCS) in the} German power sector and comparison with the deployment of renewable energies

a Wuppertal Institute for Climate, Environment and Energy, Germany

* Corresponding author: Peter Viebahn, Wuppertal Institute, Döppersberg 19, 42103 Wuppertal, Germany

E-mail: peter.viebahn@wupperinst.org

Phone: +49-202-2492306

Fax: $\quad+49-202-2492198$ 


\begin{abstract}
If the current energy policy priorities are retained, there might be no need to focus additionally on carbon capture and storage (CCS) in the power plant sector of Germany. This applies even in the case of ambitious climate protection targets, according to the results of the presented integrated assessment study. These cover a variety of aspects: Firstly, the technology is not expected to become available on a large scale before 2025 in Germany. Secondly, if renewable energies and combined heat and power are expanded further and energy productivity is enhanced, there is likely to be only a limited demand for CCS power plants as a scenario analysis of CCS deployment in Germany shows. Thirdly, cost analysis using the learning curve approach shows that the electricity generation costs of renewable electricity are approaching those of CCS power plants. This leads to the consequence that from 2020, several renewable technologies may well be in a position to offer electricity at a cheaper rate than CCS power plants. In addition, a review of new life cycle assessments for $\mathrm{CO}_{2}$ separation in the power plant sector indicates that the greenhouse gas emissions from one kilowatt hour of electricity generated by first-generation CCS power plants could only be reduced by 68 to 87 per cent (95 per cent in individual cases). Finally, a cautious, conservative estimate of the effective German $\mathrm{CO}_{2}$ storage capacity of approximately 5 billion tonnes of $\mathrm{CO}_{2}$ is calculated, including a fluctuation range yielding values between 4 and 15 billion tonnes of $\mathrm{CO}_{2}$. Therefore, the total $\mathrm{CO}_{2}$ emissions caused by large point sources in Germany could be stored for 12 years (basic value) or for 8 respectively 33 years (sensitivity values).
\end{abstract}

\title{
Keywords
}

CCS; Germany; integrated assessment; renewable energy

\section{Introduction}

In Germany, the discussion on CCS has gained a particularly high degree of public attention as the country is pursuing ambitious $\mathrm{CO}_{2}$ mitigation targets of minus 40 per cent until 2020 and at least minus 80 to 95 per cent until 2050 (both compared to 1990 levels). At the same time the country is being the European Union's (EU) largest coal producer, with about 44 per cent of its electricity supply coming from coal-fired power plants [1]. The heated CCS debate calls for a profound and integrated scientific analysis which takes into account all dimensions affecting the deployment of the CCS technology in Germany - including "hard" and "soft" aspects. "Hard" aspects encompass technical, economic and environmental parameters of CCS, the available national $\mathrm{CO}_{2}$ storage capacity as well as a long-term scenario analysis of the technology's potential in Germany. "Soft" aspects comprise the role of stakeholders and public acceptance and the regulatory framework for CCS in Europe and Germany. While the Wuppertal Institute together with other research organisations has presented a first integrated assessment of CCS for Germany in 2007 which compared the technology's potential with renewable energy technologies [2], in the meantime several determining factors changed. These are the technical development of both CCS and renewable energy technologies, an increasing critical public discussion on CCS as well as ambitious national and European renewable energy targets set in the EU's "green package" at the end of 2008 [3]. Therefore the former study was enhanced and updated to submit a more comprehensive assessment of CCS than done three years ago [4].

To our knowledge, no similar assessment has been published before, not for Germany or abroad. One integrated assessment available for CCS, published in 2006, refers to the UK [5]. However, it does not include a comparison with renewable energies, nor does it consider the 
compatibility of CCS with renewable energies and other options within energy scenarios at the UK level. Instead, it covers geological storage, risks and potential impacts of leakage, legal aspects of geological $\mathrm{CO}_{2}$ storage, technical and economic feasibility, and public acceptability. The presented paper firstly goes through the methodologies, applied in the individual assessment aspects of the study (due to limited length, only the "hard" aspects are discussed). Secondly the outcome of each assessment step is shown. Thirdly, the authors combine the assessment dimensions to present an overall result from an integrated perspective and to recommend where and how to proceed in the current CCS debate. The paper closes with an outlook on the needs for future research.

\section{Methodology}

In this paper, an integrated approach is chosen for the assessment of CCS in the power plant sector since CCS would be part of a complex and dynamic energy system. However, each dimension of the system considered in this paper is being investigated with its specific scientific methods.

(1) The large-scale availability of the CCS technology is based on a screening of technical studies, presentations as well as statements of German and international CCS experts on the current state and expected course of development of the CCS in the coming years. Furthermore, the progress of on-going or planned CCS demonstration projects in Germany was studied.

(2) Energy scenario analysis is used to analyse the future role, CCS could play in the electricity sector in comparison to renewable energies in Germany. The use of CCS is depicted in a scenario family "CCS-REN/CHP", comprising six variants of the expansion of CCS capacity. These scenarios are based on the Lead Scenario 2008 of the German Ministry for the Environment which aims to reduce energy related $\mathrm{CO}_{2}$ emissions by 80 per cent in 2050 , compared to 1990 level. Since neither nuclear energy nor CCS will be used in the base scenario in 2050 a large amount of both installed capacity $(71 \%)$ and electricity generation $(66 \%)$ is based on renewable electricity (130 out of $184 \mathrm{GW}$ and 419 out of $635 \mathrm{TWh} / \mathrm{a}$, respectively). The remaining fossil load is mainly based on coal and natural gas. [6]

For our scenarios, it is assumed that energy policy targets set by the German government and incorporated into in the Lead Scenario will indeed be implemented. These targets are doubling the energy productivity by 2020 compared to 1990 levels; a 25 per cent share of combined heat and power generation (CHP) in 2020 and the required significant expansion of renewable energies (REN) (a 30 to 35 per cent share of renewable energies in electricity generation by 2020 and an approximately 50 per cent share by 2030). However, it is assumed that the necessary efficiency measures will only be realised to a moderate extent if implementing energy efficiency strategies would be delayed. The varying use of CCS is envisaged for the remaining demand for electricity from fossil sources, and the overall target is to determine under which of the CCS based scenarios the climate target could be reached as well. The other default values on the development of a renewable energy mix as well as CHP are adopted unalteredly.

While the upper variant of the scenario family, "Maximal-theoretical", assumes that each new power plant will either be CCS-based or retrofitted later on, the lower variant "Realistic II" foresees only 50 per cent of newly built steam power plants and 30 per cent of newly built CHP plants being based on CCS and only 30 per cent and 15 per cent of older ones retrofitted, respectively. The remaining scenarios are situated between the upper and the lower variant (see Table 1). A differentiation is made between new power plants and retrofitted power plants commissioned between 2010 and 2020 as well as between large-scale condensation power stations and CHP plants, which generally have less capacity. It is furthermore assumed that new fossil fuel-fired power plants built between 2005 and 2010 will be replaced by new CCS power plants at the end of their operating time, i.e. between 2045 and 2050. 
Table 1: Share of power plants equipped with CCS in the six variants of CCS-REN/CHP scenarios

\begin{tabular}{lcccc}
\hline Scenario variants & \multicolumn{2}{c}{ Condensing power plant } & \multicolumn{2}{c}{ Combined heat and power plant } \\
& New & Retrofitting & New & Retrofitting \\
\hline 1. Maximal - theoretical & $100 \%$ & $100 \%$ & $100 \%$ & $100 \%$ \\
2. Maximal - realistic & $100 \%$ & $65 \%$ & $75 \%$ & $35 \%$ \\
3. Maximal - new & $100 \%$ & - & $75 \%$ & - \\
4. Realistic I & $75 \%$ & $40 \%$ & $40 \%$ & $20 \%$ \\
5. Realistic I (only coal) & $75 \%$ & $40 \%$ & $40 \%$ & $20 \%$ \\
6. Realistic II & $50 \%$ & $30 \%$ & $30 \%$ & $15 \%$ \\
\hline
\end{tabular}

(3) Analysing the development of levelised cost of electricity generation (LCOE), the investment costs as well as the operating costs for CCS based power plants are based on a literature review while those of renewable energies are cited from [6]. In both cases, the learning curve approach is used to update future investment costs, while the LCOE are calculated using the annuity method. The basic figures used for our assessment are given in Table 2 .

Table 2: Basic parameters of "early commercial" CCS power plants in 2020, "mature commercial" CCS power plants in 2040 and their reference power plants without $\mathrm{CO2}$ capture

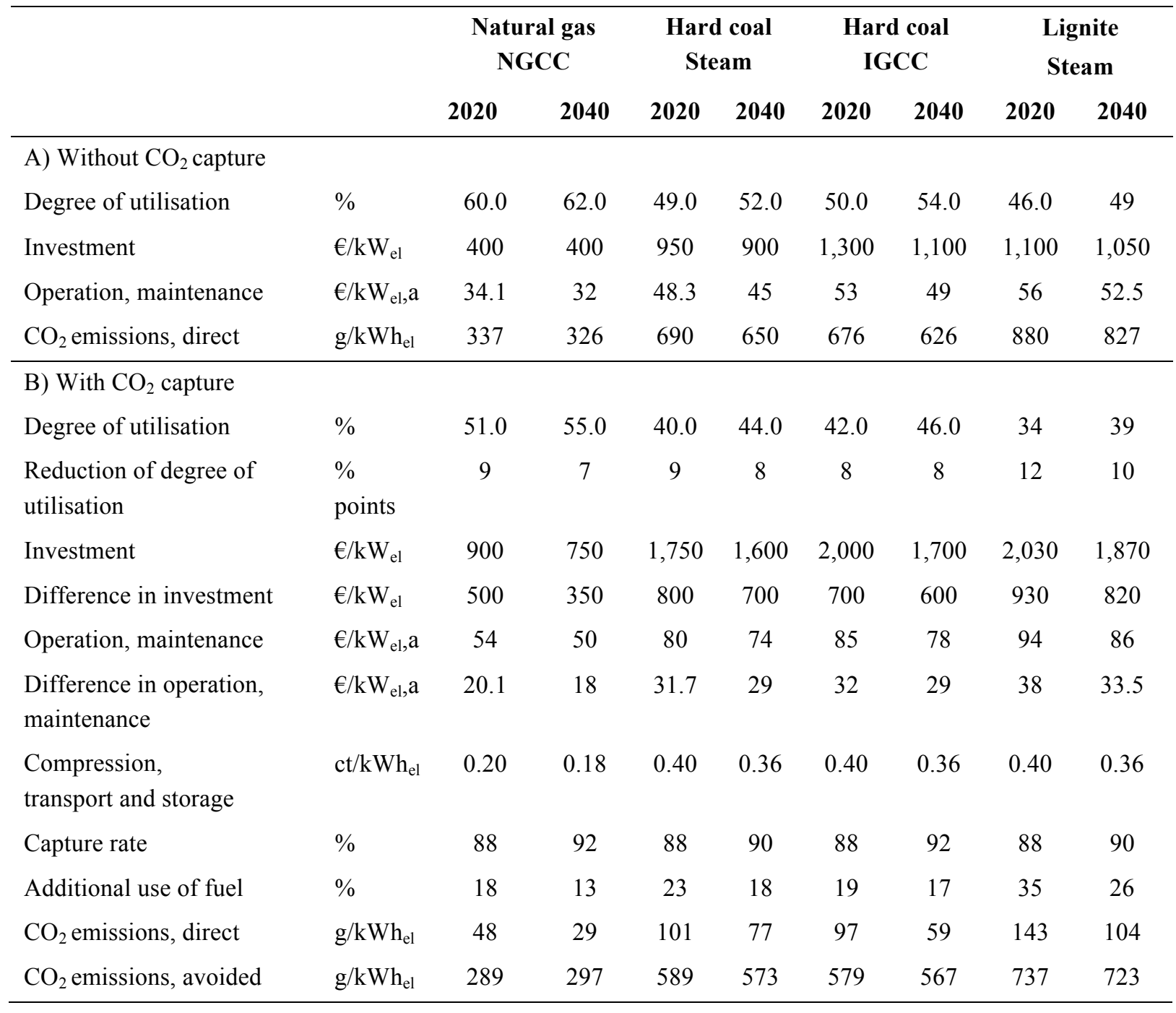


Since energy price trajectories are the most influential factors in calculating the LCOE, three different variants ("considerable", "moderate" and "very low") are considered (taken from [6]). The price of hard coal develops to $9.85,6.05$ and $4.15 € / \mathrm{GJ}_{\text {th }}$ fuel in the year 2050, respectively while the price of natural gas develops to $18.52,12.10$ and $8.51 € / \mathrm{GJ}_{\mathrm{th}}$, respectively. Similarly, three trajectories for $\mathrm{CO}_{2}$ allowances are considered which develop to 70,45 and $28 € / \mathrm{t} \mathrm{CO}_{2}$, respectively. It should be noted that no least-cost optimisation model is used, since our study assesses CCS against the background of given strong increasing shares of renewable energies while phasing out nuclear energy, as is the case in Germany. Therefore the possible capacity of CCS is based on the targets for the development of renewable energies and efficiency given by the scenarios.

(4) The aim of the environmental assessment is to review existing life cycle assessment (LCA) studies on CCS and to compare the environmental impacts with those of selected renewable energy plants as well as with the first LCA done in [2]. Only such studies are reviewed in which an LCA was carried out in accordance to the relevant standards (ISO 14.040 and 14.042) and which considered several environmental impact categories. Studies that included either only greenhouse gas emissions or only the power plant without the upstream and downstream chains were not included. Besides an LCA from the former RECCS study [2], four studies considering CCS in Germany or Europe and published in 2008 and 2009 were selected $[5,6,7,8]$.

(5) The most crucial step within the whole CCS process chain is the underground storage of $\mathrm{CO}_{2}$. Since the political discussion rarely considers the potentially available storage capacities, the objectives of our storage capacity assessment analysis are twofold:

(i) In the first step the existing capacity estimates for Germany $[16,19,20,21]$ are systematically analysed and compared with regard to their methods and assumptions.

(ii) Since basic parameters used in the reviewed studies were either not published or not backed up adequately, in the second step, an own cautious, conservative estimate for the effective capacity is presented. The intention is to provide a lower limit for the storage space for orientation purposes for potential investors and political decision-makers. In this sense the own estimate can be seen as a sensitivity analysis complementing the reviewed studies in which the most crucial parameter, the efficiency factor, is varied.

After finalising our report a new study from the German Geological Survey (BGR) [28] was provided which is compared with our results.

When calculating storage potentials, a methodological distinction is made between a "topdown" and a "bottom-up" approach. In the "top-down" approach, a total volume (for example, for the whole of Germany) is assumed. This total volume is then restricted according to various criteria like sufficient porosity, density of $\mathrm{CO}_{2}$, share of closed structures etc. ("volumetric concept"). The resulting "theoretical potential" is further reduced to the "effective potential" by applying an "efficiency factor" which takes potential water displacement and compressibility into account. Using the "bottom-up" method, single structures are considered and their capacities added together to calculate the total storage potential. While the volumetric concept is usually used for aquifers, the "bottom-up" approach is generally applied for hydrocarbon fields.

It is evident that a general top-down approach can only provide unsecure results and a sitespecific analysis for all potential storage sites is needed in order to decrease the uncertainty range. That's why some new aquifer assessments rely also on the bottom-up approach but do not provide results for the entire country so far. Therefore, in our study, only existing studies which consider saline aquifers (onshore and offshore) and hydrocarbon fields for Germany in total, are considered (see [4] for a detailed analysis). 


\section{Outcomes of the integrated assessment}

\subsection{Large-scale availability of the CCS technology}

As the CCS draft law of the German Federal Government [16] explicitly limits the scale and scope of CCS activities in Germany to pilot and demonstration scale with a total of annually 8 million tonnes of $\mathrm{CO}_{2}$ to be stored until 2017 , it is likely to delay the applicability of integrated CCS systems at large scales. Usually the process of scaling-up technologies from the demonstration stage to actual commercialisation requires several years, and starting demonstration in 2015 makes commissioning of commercialised power plants before 2025 unlikely [17]. Furthermore, energy utilities might retard planning and financing large-scale power plants if the implementation of a "full" CCS law after 2017 is rather unclear. Besides the development of the CCS plant itself, a transport infrastructure and safe storage systems have to be in place, requiring further years for planning, testing and implementation. Altogether, in Germany the whole CCS chain might not be available in commercial dimensions before 2025 to 2030 .

The expected delay of the large-scale availability of CCS in Germany is unlikely to have a strong influence on the development of the world market. Nevertheless, some experts from scientific institutions and from NGOs increasingly refer to the years between 2025 and 2030 as the time by which the technology will be ready for operation $[18,19,20]$. By inhibiting technology learning processes and cost reductions, this delay could affect the bridging function of CCS which is often said to be a key step towards a renewable-based energy system.

\subsection{Energy scenario analysis on the available $\mathrm{CO} 2$ emissions for storage under an ambitious climate protection policy in Germany}

For two out of the six scenario variants developed in this study, the installed CCS capacity and the avoided $\mathrm{CO}_{2}$ emissions are given in detail. The from our point of view most realistic variant ("Realistic I") results in an installed CCS capacity of $20 \mathrm{GW}$ (not including penalty load) in 2050 and a $\mathrm{CO}_{2}$ reduction of 46 million tonnes, compared with an equally sized electricity generation without CCS. This amount constitutes 18 per cent of the total avoidable $\mathrm{CO}_{2}$ emissions in the electricity sector between 2005 und 2050, and 8 per cent of that within the entire power supply. In this case, electricity generation from CCS power plants would make up a 12 per cent share of the total power generation in 2050 (see Figure 1) and an 11\% share of total installed power in 2050 (see Figure 2). 64 million tonnes of $\mathrm{CO}_{2}$ would have to be stored underground annually in 2050 while the cumulated amount from 2020 to 2050 would result in 1.19 billion tonnes of $\mathrm{CO}_{2}$.

For comparison, in the case of a maximum CCS implementation strategy ("Maximumtheoretical"), $41 \mathrm{GW}$ of CCS based capacity could be installed in 2050, which is 22 per cent of the totally installed load, thereby saving 85 million tonnes of $\mathrm{CO}_{2}$ and requiring 117 million tonnes of $\mathrm{CO}_{2}$ to be stored in 2050. In this case, the cumulated amount from 2020 to 2050 would result in 2.15 billion tonnes of $\mathrm{CO}_{2}$. 


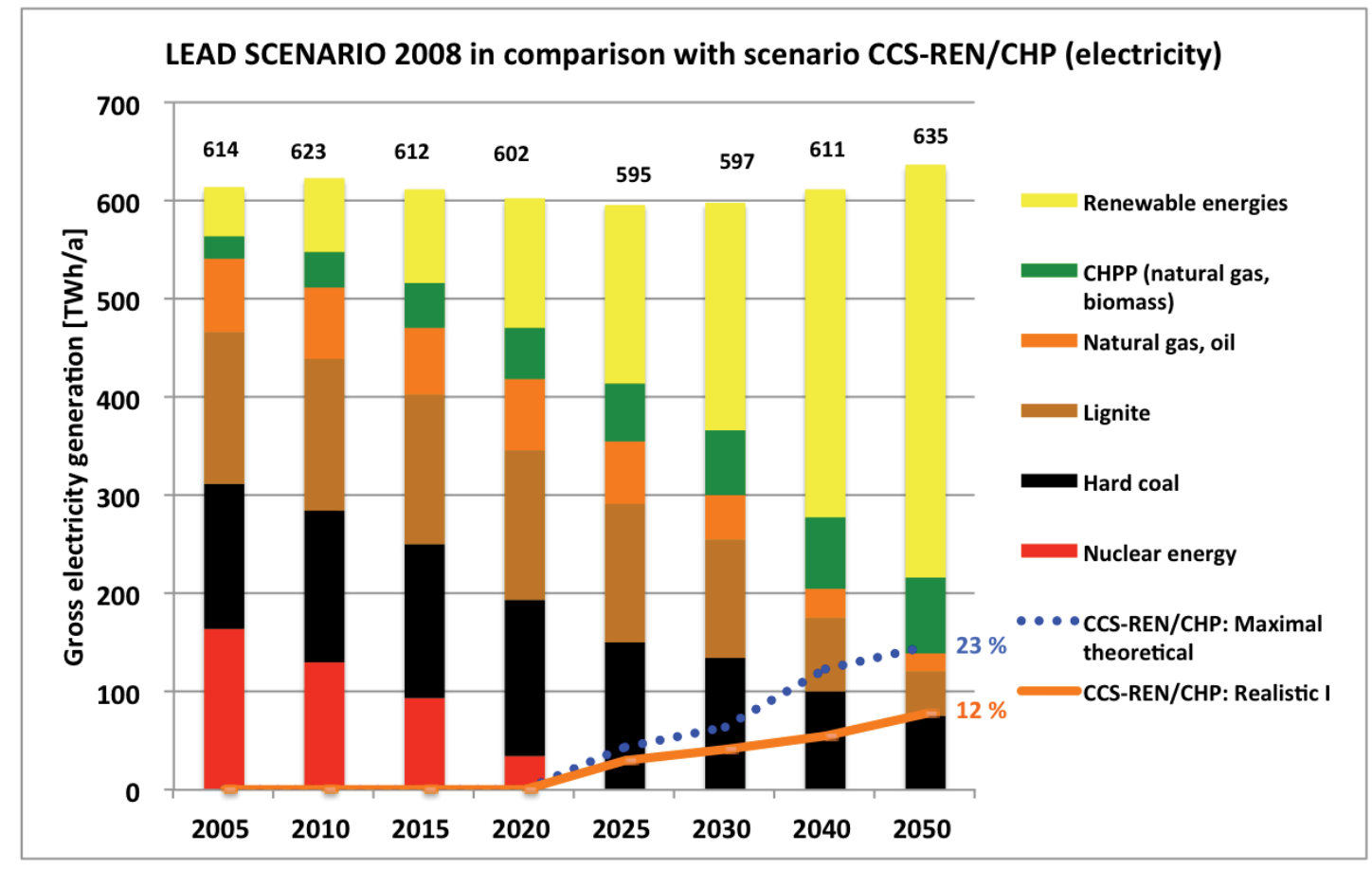

Figure 1: Overall electricity generation in the Lead Scenario 2008 and contribution of CCS in two variants of scenario CCS-REN/CHP

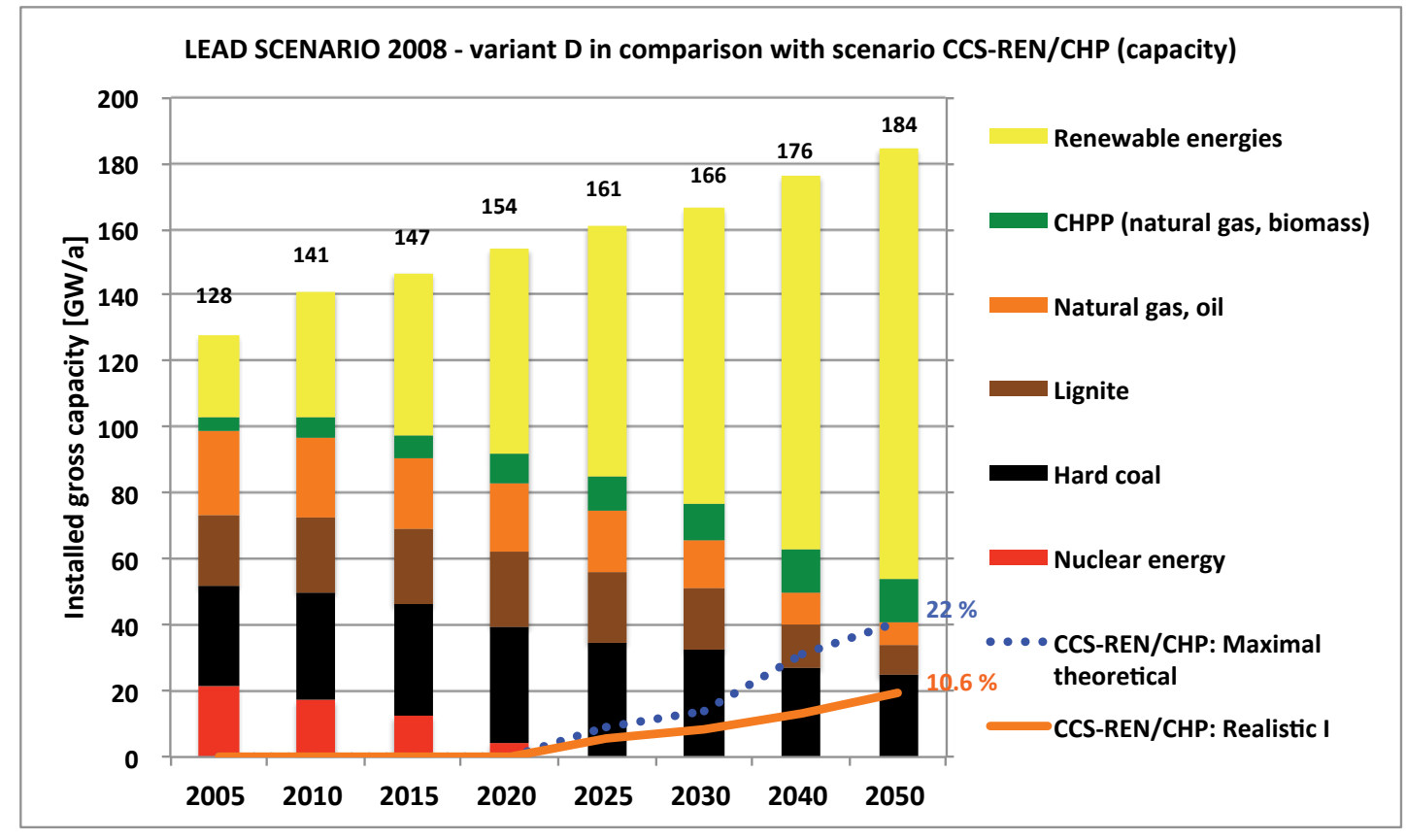

Figure 2: Overall power plant capacity development in the Lead Scenario 2008 and contribution of CCS in two variants of scenario CCS-REN/CHP

Figure 3 illustrates, that the scenario variant "Maximal-theoretical" would exceed the envisaged climate targets in the electricity sector (reaching 10.5 million tonnes of $\mathrm{CO}_{2}$ in 2050 instead of 28 million tonnes), while scenario "Maximal-realistic" virtually reaches the target exactly. But the variants "Realistic I" and "Realistic II" would miss the target by 78 to 125 per cent, reaching only levels of 50 and 63 million tonnes of $\mathrm{CO}_{2}$ in 2050. Applying no CCS, on the other hand, would result in 100 million tonnes of $\mathrm{CO}_{2}$ in 2050, which is caused - according to the scenario assumptions - by the insufficiently implemented energy efficiency measures.

Furthermore it becomes apparent that the $\mathrm{CO}_{2}$ reductions achieved by expanding renewable energies could be considerably larger for the same period (curve "renewables frozen"). 
However, it would necessitate a considerable restructuring of the power industry and infrastructure - including the need for not only completely different transmission network structures but also energy storage facilities.

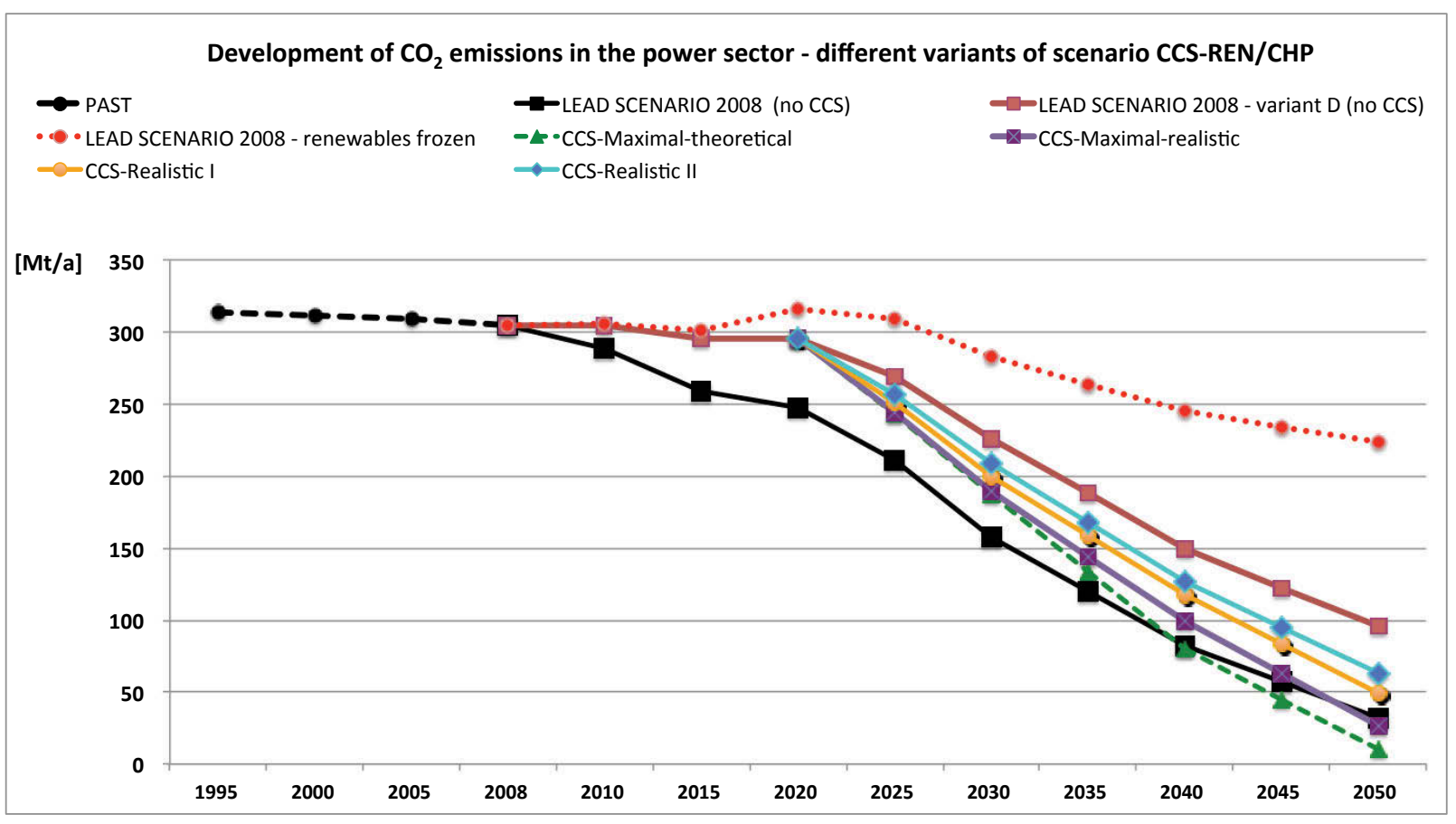

Figure 3: Development of $\mathrm{CO} 2$ emissions in the German electricity sector in the different variants of scenario CCS-REN/CHP compared with the original Lead Scenario 2008

The quantities of electricity that can be generated in these power plants are the result of the concurrence of all power-generating plants to meet the respective demand. The significant expansion of renewables and the intended higher share of CHP will have an increasing impact on the utilisation period of fossil fuel-fired power plants because the base load operation will gradually decrease. Their capacity factor will decrease from an average of 5,600 h/a in 2010 to $3,600 \mathrm{~h} / \mathrm{a}$ in 2050 .

\subsection{Development of power production cost: The race in learning effects between CCS backed fossil fuels and renewable energies}

\subsubsection{Levelised electricity generation cost of CCS based power plants}

After successfully demonstrating the entire CCS chain (capture, transport and, in particular, storage of $\mathrm{CO}_{2}$ ) and reaching the stage of commercial availability, according to our calculations, electricity generating costs of CCS power plants ranging from 7.30 and 10.35 $\mathrm{ct} / \mathrm{kWh}_{\mathrm{el}}$ (at power plant) can be achieved by 2020 (assumed real interest rate 6 per cent per annum). The price range depends on both the technology taken into consideration and the price trends of fuel and $\mathrm{CO}_{2}$ allowances up to 2020 (see section 1).

Out of several scenarios which differ by an increase of both fuel cost and of $\mathrm{CO}_{2}$ penalties in the range of $\mathrm{A}=$ "considerable", $\mathrm{B}=$ "moderate" and $\mathrm{C}=$ "very low", the results of two extreme scenarios are given here: (1) very low increasing fuel costs and high $\mathrm{CO}_{2}$ penalties (scenario $\mathrm{C} / \mathrm{A}$ ) and (2) considerably rising energy costs that cause a surplus of and, therefore, decreasing $\mathrm{CO}_{2}$ penalties (scenario $\mathrm{A} / \mathrm{C}$ ). In the latter case, considered to be the more realistic scenario from our point of view, $\mathrm{CO}_{2}$ avoidance costs in 2020 of $68 € / t \mathrm{CO}_{2}$ (natural gas), $34 € / t \mathrm{CO}_{2}$ (hard coal) and $20 € / \mathrm{t} \mathrm{CO}_{2}$ (lignite) are produced.

Depending on further price trends, the long-term cost projections of CCS range from 8.10 to $13.80 \mathrm{ct} / \mathrm{kWh}_{\mathrm{el}}$ in 2040 and from 8.80 to $15.40 \mathrm{ct} / \mathrm{kWh}_{\mathrm{el}}$ in 2050 (see Figure 5). Lignite steam 
power plants are in the lower range, hard coal power plants (steam and gasification) are in the medium to high range, and natural gas in the top range. $\mathrm{CO}_{2}$ avoidance costs change due to learning effects as well as fuel price and $\mathrm{CO}_{2}$ price development in scenario $\mathrm{A} / \mathrm{C}$ by 2040 to 61 $€ / \mathrm{t} \mathrm{CO}$ (natural gas), $36 € / \mathrm{t} \mathrm{CO}_{2}$ (hard coal) and $17 € / \mathrm{t} \mathrm{CO}_{2}$ (lignite).

The influence of both increasing fuel costs and decreasing capacity factor is illustrated in Figure 4, using scenario $\mathrm{A} / \mathrm{C}$ as an example. While the investment cost decrease due to learning effects, the annual cost increase due to continuously decreasing full load hours. This also effects the O\&M costs which slightly increase. But the fuel costs which increase considerably in this scenario have a much higher impact on the total LCOE.

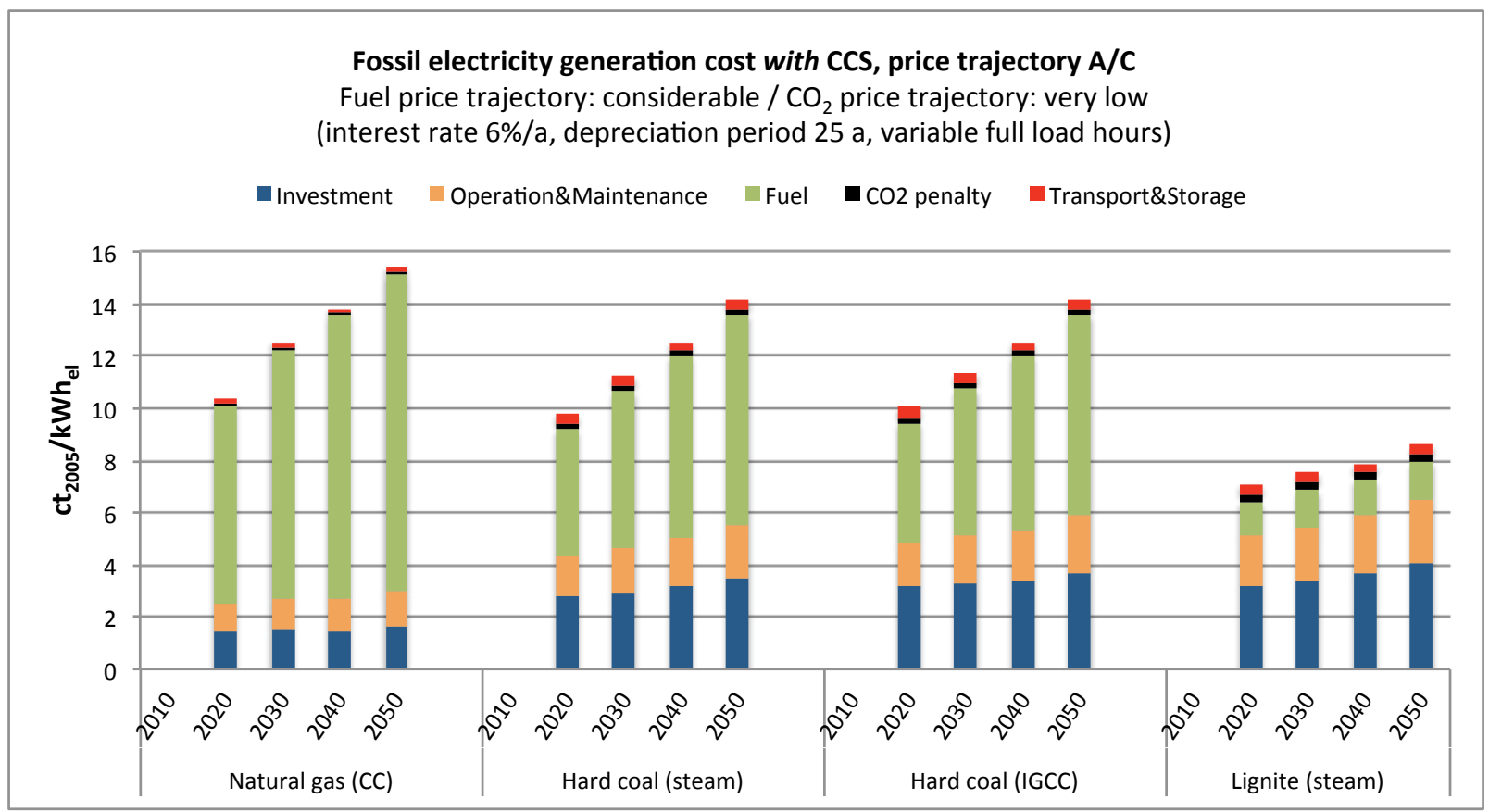

Figure 4: Composition of levelised electricity generating costs (new plants) for natural gas (combined cycle), hard coal (steam), hard coal (IGCC) and lignite (steam) power plants (considerable fuel price increase, very low $\mathrm{CO} 2$ price increase) (with CCS)

\subsubsection{Comparison with electricity generation cost from renewable energies}

To compare LCOE of CCS with electricity from renewable energies, the estimated development of renewable electricity is taken from the Lead Scenario 2008 [6]. Accordingly, in 2008 the average electricity generating costs of renewable energies in Germany were around 12 $\mathrm{ct} / \mathrm{kWh}_{\mathrm{el}}$, assuming a representative mix (also calculated at a real interest rate of 6 per cent per annum). When photovoltaics is excluded from the mix, the average costs amounted to around $10 \mathrm{ct} / \mathrm{kWh}_{\mathrm{el}}$. If renewable energies continue to be launched at a similar speed as before, average electricity generating costs of approximately $8.8 \mathrm{ct} / \mathrm{kWh}_{\mathrm{el}}$ (including photovoltaics) and 8.2 $\mathrm{ct} / \mathrm{kWh}_{\mathrm{el}}$ (excluding photovoltaics) could be achieved by 2020. A sustained global increase in market penetration and learning effects give reasons to expect further significant cost degressions for renewable energies over time. By 2050, therefore, the level of costs in the investigated characteristic mix could be around $8.8 \mathrm{ct} / \mathrm{kWh}$ l. Technologies such as offshore wind power or geothermal energy could achieve electricity costs of around $5 \mathrm{ct} / \mathrm{kWh}_{\mathrm{el}}$ if their learning curve continues to be used for the further expansion of global markets. For comparison with CCS, Figure 5 illustrates both the development of an assumed renewable mix with and without photovoltaics and offshore wind. 


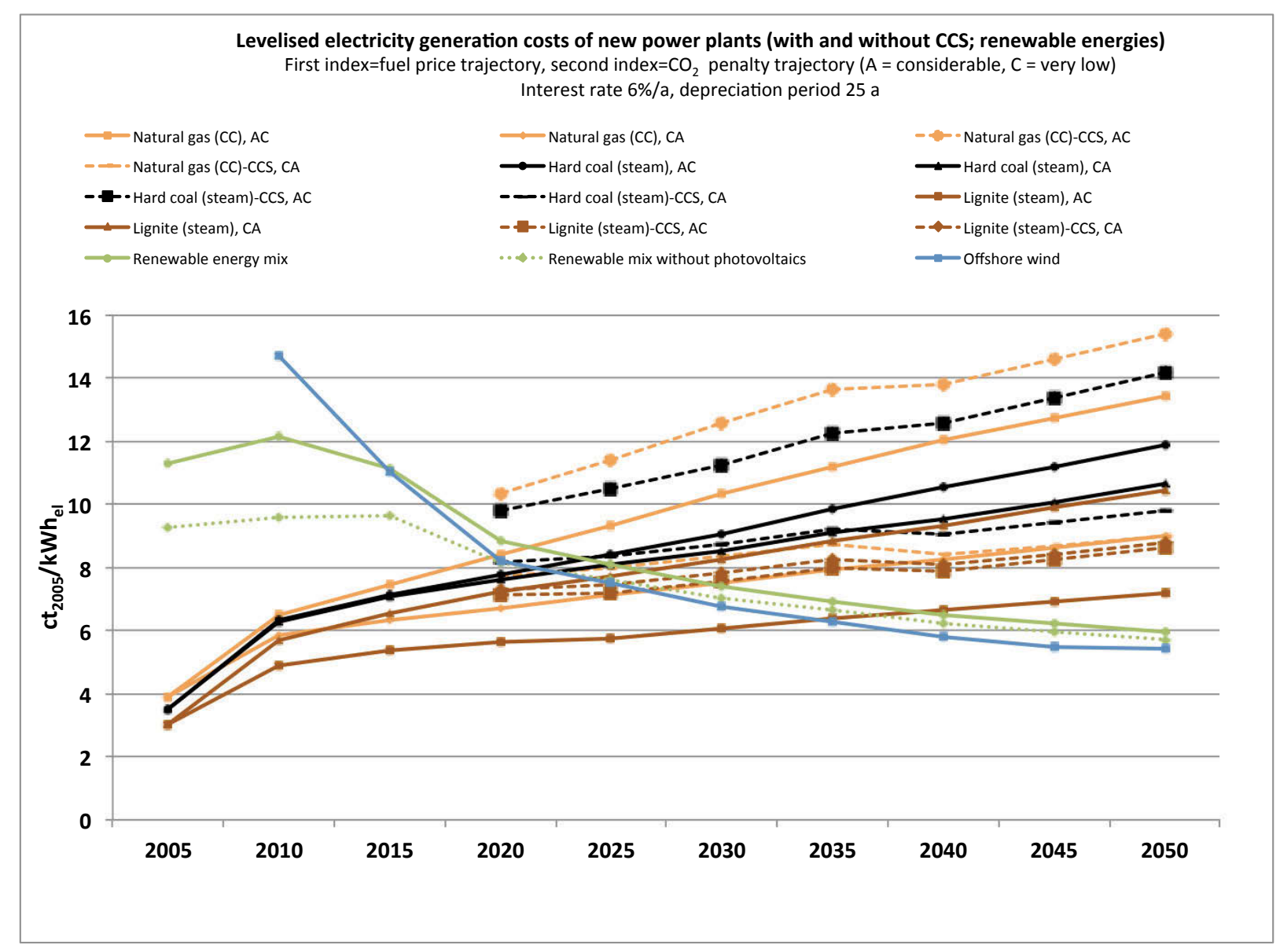

Figure 5: Development of future levelised electricity generating costs (new plants) for renewable energies and fossil fuel-fired power plants (with/without $\mathrm{CCS}$ ) for price trajectories $\mathrm{A} / \mathrm{C}$ and $\mathrm{C} / \mathrm{A}$ (CCS from 2020, including transport and storage)

If the dynamics of the expansion of renewable energies in the electricity sector remains high, as assumed in the scenario family "CCS-REN/CHP" (section 2.2), individual renewable energy technologies (offshore and onshore wind power, solar thermal power plants) will be able to compete with CCS power plants as early as in 2020. If fuel prices increase considerably, the generating costs of CCS-based natural gas- and hard coal-fired power plants will be higher from 2020 than for renewable energies. Lignite-fired CCS power plants will follow from 2025 (higher cost than offshore wind/solar thermal energy) and 2030 (higher cost than the mix of renewable energies). Even in the case of very small increases in energy prices, the additional costs incurred by CCS would be so high that renewable energies would remain competitive at the same time as in the high price scenario. The high $\mathrm{CO}_{2}$ penalty, which cannot be fully compensated by $\mathrm{CO}_{2}$ capture, has a particularly powerful impact on lignite.

\subsection{Assessment of environmental impacts of CCS and renewable energies based electricity generation in a life cycle assessment perspective}

\subsubsection{Environmental impacts of CCS based electricity generation}

Considering the four existing life cycle assessments $[7,8,9,10]$ reviewed for this study, the findings of [2] for post-combustion were mainly confirmed, even if in the latest studies (in particular, by [8]) the capture and, in part, transport and storage were modelled in more detail. Substantial new findings were generated for pre-combustion and oxyfuel, despite the fact that the capture processes have not yet been considered in detail. The only value given in all of the studies is that of greenhouse gas (GHG) emissions, consisting mainly of $\mathrm{CO}_{2}, \mathrm{CH}_{4}$ and $\mathrm{N}_{2} \mathrm{O}$ emissions. They are particularly relevant in the case of hard coal- and natural gas-fired power 
plants because considerable methane emissions $\left(\mathrm{CH}_{4}\right)$ are created here in the upstream chains. This effect is intensified by the increased energy consumption of CCS power plants. The capture rates and initial emissions in 2020 are generally assumed to be identical in all studies. Considerable deviations are visible, however, in the reduction of GHG emissions. The reason for this is that varying assumptions are made on the additional energy consumption caused by capture, and hence the reduction in the degrees of utilisation. The following GHG reduction rates per kilowatt hour of electricity are given for 2020/2025, based on $\mathrm{CO}_{2}$ capture rates of around 90 per cent:

- Hard coal: steam (67 to 72 per cent), oxyfuel (78 and 85 per cent), IGCC (68 and 67 per cent)

- Lignite: steam (78 to 81 per cent), oxyfuel (87 and 95 per cent), IGCC ( 83 and 84 per cent)

- $\quad$ Natural gas: steam (67 and 75 per cent).

However, other environmental impacts should be considered in addition to GHG emissions. A CCS based power plant requires higher energy resources as well as additional materials used in the capture processes, for which the necessary upstream processes (for example, the production of the detergent used for $\mathrm{CO}_{2}$ capture) are also modelled within a life cycle assessment. The additional energy and material flows can be perceived in direct proportion to the various impact categories of the LCA. Depending on the assumptions made in the reviewed studies, the various interactions in the capture processes lead to many trade-offs in the individual environmental impact categories. In some studies, all emissions increase in accordance with the additional energy consumption (for example the potentials of eutrophication, abiotic depletion, photochemical oxidation the human toxicity). Other studies, however, model trade-offs that arise from the simultaneous reduction of other emissions in the course of the $\mathrm{CO}_{2}$ capture process (for example the acidification potential).

After finishing our study recently a new comparative life cycle assessment of coal and natural gas fired power plants has been published [21]. Modelling CCS based power plants based on the best technologies currently available, the authors come to similar conclusions (decrease of global warming potential by 64 to 78 per cent, different trade-offs for other impact categories depending on the technology used).

\subsubsection{Comparison with electricity generation from renewable energy sources}

For the comparison with renewable energies, only GHG emissions are taken into account since they are the only emissions reported in all considered CCS studies. While the figures for 2020/2025 average over all studies, for 2050 we use the results from [7]. In the referred NEEDS project also a number of renewable energies were investigated in terms of their future development, based on the same back ground processes and energy scenarios as used for the assessment of CCS. These are offshore wind power [22], photovoltaics [23] and solar thermal power plants [24]. The minimum and maximum values from three technology scenarios ("pessimistic", "optimistic-realistic" and "very optimistic") are selected. In case of CCS based power plants, the minimum and maximum values and the mean of all options, considered in the former section, are given. The range results from combining steam power plants and IGCC. 


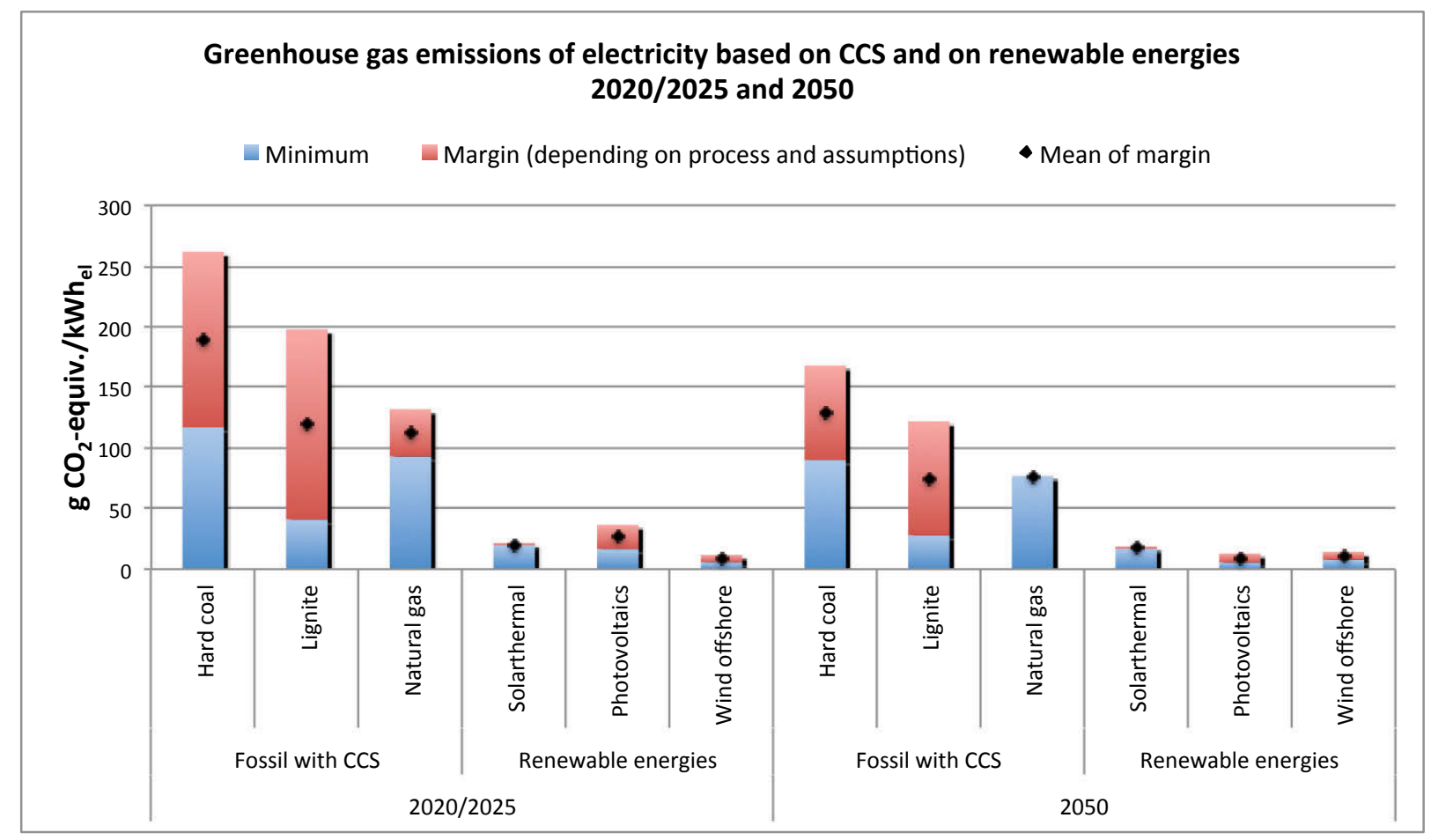

Figure 6: Greenhouse gas emissions from fossil fuel-fired power plants with CCS in comparison with electricity from renewable energies (solar thermal power plants, photovoltaics and offshore wind, each in 2020/2025 and in 2050)

Figure 6Figure 6 shows that renewable energies, even compared to CCS power plants, create only a fraction of GHG emissions (most of which originate from the construction of the plant). The chart illustrates that in 2025 , offshore wind creates only 5 to 8 per cent, solar thermal energy 11 to 18 per cent and photovoltaics 14 to 24 per cent of the emissions of CCS power plants. By 2050, photovoltaics improve, in particular, releasing only 7 to 12 per cent of the emissions of CCS power plants; offshore wind creates 9 to 15 per cent and solar thermal energy 13 to 23 per cent.

\subsection{Available storage capacity in Germany}

The storage capacity for different German formations is presented in two steps. First, the existing studies are resumed. Second, our own, conservative estimate is presented.

\subsubsection{Aquifers (onshore)}

\section{Step 1: Analysis of existing studies}

In the assessed studies (see Table 3 and Figure 7), a large range is provided by onshore aquifers $(0.5$ to $42 \mathrm{Gt})$ where the efficiency factor is the most significant parameter. The arbitrarily chosen factor ranges from 2 to 40 per cent, that means a variation of a factor of 20 . The different values for the efficient factors depend on whether closed or open systems are considered and to which volume (either the trap volume of an aquifer or the total pore volume) the estimate refers. The density of the $\mathrm{CO}_{2}$ varies between 600 and $700 \mathrm{~kg} / \mathrm{m}^{3}$ which causes smaller deviations between 14 and 17 per cent.

\section{Step 2: Own, conservative estimate}

For aquifers, we take mainly into account that the underground pore space of aquifers is saturated with saline water. Thus the available pore space is only usable to a small extent for $\mathrm{CO}_{2}$ storage if displacement of this strong saline water is to be avoided. If no formation water is produced out of the aquifer, the efficiency is controlled by the maximal allowable pressure 
increase in the system [25]. Furthermore, it is assumed that $\mathrm{CO}_{2}$ can only be injected into trap structures. Many authors justify this limitation because of its higher permanence in the formation, leading to greater public acceptance. In order to minimise the risk of potential seepage of saline water into drinking water or other environments due to injection of $\mathrm{CO}_{2}$ underground, every geological system is viewed as being closed so that the prevailing formation water and the injected $\mathrm{CO} 2$ stay in this very system.

Taking into account a corresponding lower total pressure increase in the system (1 MPa) to prevent fracturing and a low compressibility of pores and water $\left(1 * 10^{-3} / \mathrm{MPa}\right)$, an efficiency factor of 0.1 per cent is achieved by multiplication of these parameters, applicable to the total onshore aquifer volume. These assumptions are confirmed by recent studies [26,27], which take into account the lower efficiency factors and advocate taking into consideration only closed underground systems. Based on these assumptions, the conservative estimate of the storage capacity for Germany in onshore saline aquifers amounts to 0.84 billion tonnes of $\mathrm{CO}_{2}$. A sensitivity analyses with efficiency factors 0.045 per cent (lower compressibility of $0.45^{*} 10^{-}$ ${ }^{3} / \mathrm{MPa}$ ) and 1 per cent (higher pressure increase of $10 \mathrm{MPa}$ ) yield a range of fluctuation from 0.38 to 8.4 billion tonnes of $\mathrm{CO}_{2}$.

\subsubsection{Aquifers (offshore)}

The offshore aquifers had already been estimated conservatively in the GeoCapacity report with a bottom-up approach [11]. Hence this calculation is presented here and used in our cautious estimate. It gives an average capacity of 2.9 billion tonnes of $\mathrm{CO}_{2}$ (fluctuation of 1.88 to 4.4 billion tonnes of $\mathrm{CO}_{2}$ ). These values are considerably higher than the capacities we assumed for onshore aquifers, even though German onshore aquifers are considerably larger than their offshore counterparts. This is due to the application of much higher efficiency factors than assumed for onshore aquifers because the water displacement issue has not been covered. This might be justified as saline water intrusion into the ocean water appears less harmful than contamination of potable water sources onshore.

Additionally, due to a lack of reliable data for offshore aquifers, it is impossible to carry out a comparable cautious estimate, as had been the case for onshore aquifers. But if the cautious assumptions for onshore aquifers are moderated and higher increase in pressure is permitted (upper sensitivity analysis), a different relationship between onshore and offshore results (8.4 Gt onshore towards 4.5 Gt offshore).

\subsubsection{Hydrocarbon fields}

\section{Step 1: Analysis of existing studies}

The results for depleted natural gas fields are very similar in the reviewed studies. They are based on reserve data and the assumption that 100 per cent of the extracted gas can be replaced by $\mathrm{CO}_{2}$. The storage capacity in oil fields is rather irrelevant as it is very low.

\section{Step 2: Own, conservative estimate}

New studies argue that it is rather unlikely that the entire volume of extracted gas is available for $\mathrm{CO}_{2}$ storage, that means a sweep efficiency lower than 100 per cent should be included $[28,26]$. Therefore a lower storage potential in depleted natural gas fields is achieved by including a sweep efficiency of 75 to 90 per cent. This leads to a total capacity of 1.62 to 1.94 billion tonnes of $\mathrm{CO}_{2}$, including natural gas reserves.

\subsubsection{Estimate of the total CO2 storage capacity}

\section{Step 1: Analysis of existing studies}

If all reviewed studies are compared, a wide range of values for $\mathrm{CO}_{2}$ storage capacities in Germany, ranging from 3 to 44 billion tonnes in total, is produced (see Table 3 and Figure 7). 
The biggest difference is referred to saline aquifers which are calculated top-down. Offshore basins are not even analysed in the lowest (JOULE II) and highest (GESTCO) estimates.

Table 3: CO2 storage capacities for Germany in various formations - existing and own estimations

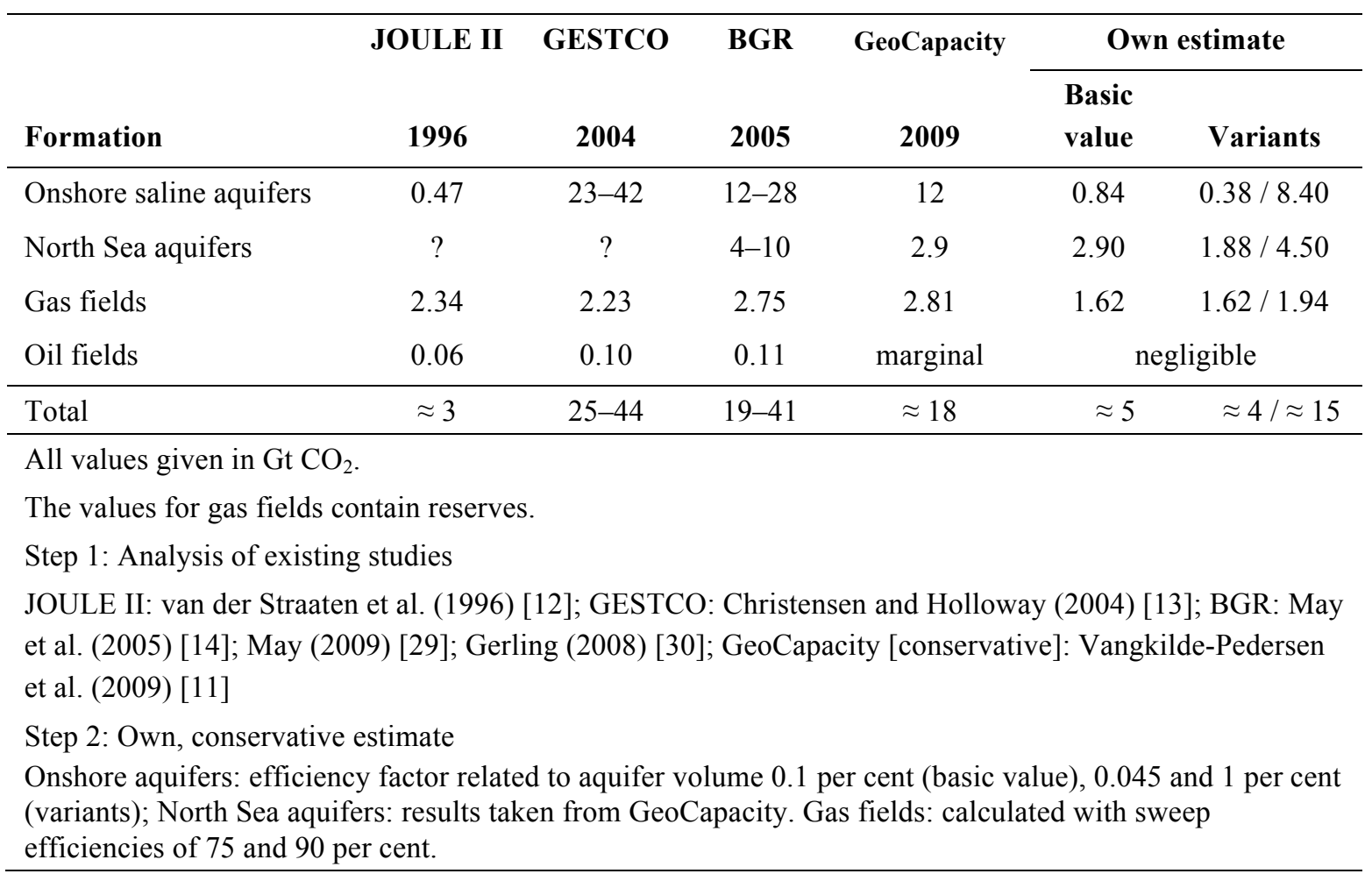

\section{Step 2: Own, conservative estimate}

Our cautious, conservative estimate for sites in Germany totals 5 billion tonnes of $\mathrm{CO}_{2}$ as the basic value. The uncertainty fluctuation yields values from 4 to 15 billion tonnes of $\mathrm{CO}_{2}$ which lie in the lower interval of the total range of all analysed studies. 


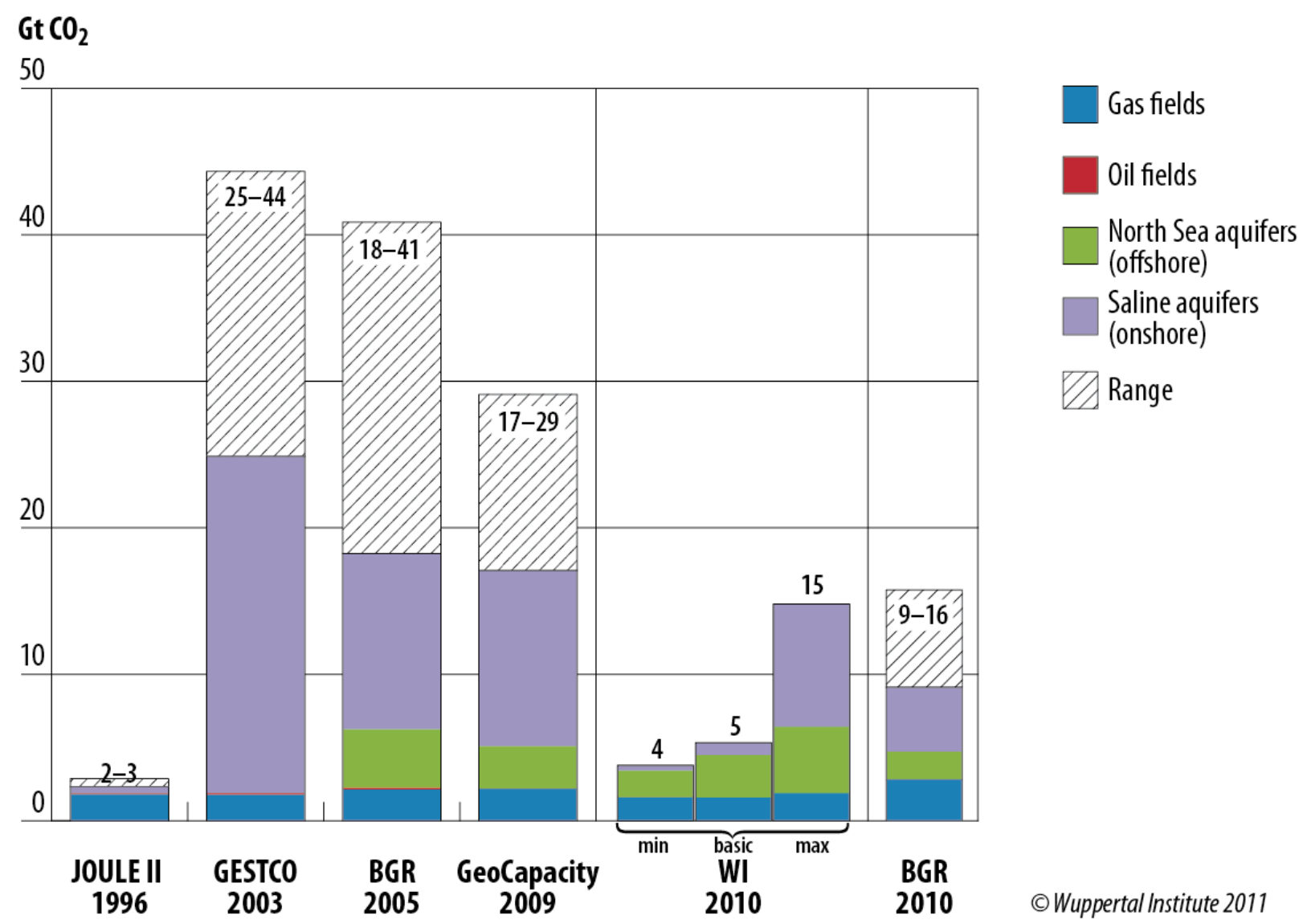

Figure 7: CO2 storage capacity estimates for Germany (reviewed studies and own estimation)

Our own estimate seems to be justified as a study of the German Geological Survey for onshore saline aquifers [15] shows, which was published shortly after providing the results of our analysis (right bar in Figure 7). The study analyses the most promising basins in Germany with a bottom-up approach. The selected onshore aquifers deliver a capacity of $6.4 \mathrm{Gt}^{\mathrm{CO}_{2}}$ (range of 4.4 to $8.3 \mathrm{Gt}$ ). The results for offshore aquifers and gas fields are taken from the GeoCapacity

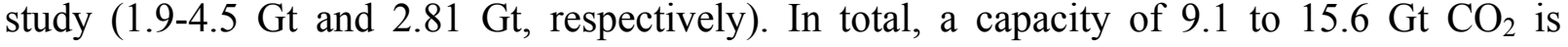
assumed which is comparable to our maximum case.

\section{Overall results and discussion}

The previous sections show that the commercialisation of CCS is affected by a broad variety of aspects. Taking into account the five assessment dimensions, leads to the overall conclusion that the framework conditions for CCS in the German power sector might not be favourable and that there might not necessarily be a need for adding CCS to German power stations.

Due to the expected late large-scale availability, the use of CCS for power plants increasingly looses the potential role ascribed to it as a bridging technology towards a renewable power system. Furthermore, the results show that the potential role of CCS largely depends on previously selected energy strategies. In the occurrence of a continued significant expansion of renewable energies and a steadily increasing share of CHP generation in the German power supply the scope for a further reduction of $\mathrm{CO}_{2}$ in the remaining fossil segment of power supply using CCS is considerably restricted. In the best outcome of the presented long-term scenario analysis 18 per cent of the total avoidable $\mathrm{CO}_{2}$ emissions in the electricity sector between 2005 and 2050 could possible be reduced. A precondition for this target is, that power stations currently under construction can be retrofitted at a later stage.

On the other hand, use of CCS technology would be prudent in a future energy supply that only achieves moderate success in increasing efficiency and further expanding renewable energies, and which shows only little change compared to the current situation with regard to its 
structural features. In that case, a different mix of renewable energies, compatible with an appropriate base-load operating CCS power plant fleet, would be necessary, a mix that is not suitable for compensating fluctuating renewable energies.

But even if CCS becomes available earlier and its potential increases, the timing of competing climate protection options must be taken into account. Depending on the fossil fuel price increase, the cost of $\mathrm{CO}_{2}$ permits and the type of fossil and renewable power plants, the electricity generating costs of CCS would become higher compared with renewable energies between 2020 and 2025. This is confirmed by [31] who proofed that in 2020 the LCOE of hydro and wind energy will be lower than those of CCS based power plants. For 2020 our $\mathrm{CO}_{2}$ avoidance costs are lower or in a similar range than those ones reported by other sources. McKinsey, for example, reports greenhouse gas (GHG) avoidance cost for Germany in the year 2020 of $95 € / \mathrm{t} \mathrm{CO}_{2} \mathrm{e}$ (natural gas), $52 € / \mathrm{t} \mathrm{CO} \mathrm{CO}_{2} \mathrm{e}$ (hard coal) and $31 € / \mathrm{t} \mathrm{CO}_{2} \mathrm{e}$ (lignite) [32]. This lies in the range of our figures if one considers that the net reduction rate of GHG emissions is lower than that one of $\mathrm{CO}_{2}$ (see chapter 2.4.1). In [33] updated figures for 2030 are given. On a global scale, $37 €_{2005} / \mathrm{t} \mathrm{CO}_{2} \mathrm{e}$ for new coal with CCS is expected while renewable electricity results in a much lower range of 14-19 $€_{2005} / \mathrm{t} \mathrm{CO}_{2} \mathrm{e}$. [34] assesses $\mathrm{CO}_{2}$ avoidance cost on a global scale of 35-50 €/t CO 2020 (early commercial phase) which drop to $30-45 € / \mathrm{t} \mathrm{CO}_{2}$ in 2030 (mature commercial phase), assuming a constant price for coal. The difference to other studies becomes viable if the long-term development is considered. Usually an increase of fossil fuel prices and a decrease of full load hours (and therefore the capacity factor) is not taken into account. Keeping these figures fixed, the LCOE of CCS would be kept much lower and the intersection with decreasing costs of renewable energies would be much later on the time axis.

Nevertheless, the influence of decreasing full load hours on performance parameters of CCS based power plants should be subject of further analysis. While on the one hand, [3335 shows how flexible CCS based power plants could contribute to balancing fluctuating renewable energies, findings from [36] show that in the future the full load hours of coal fired power plants will decline with a corresponding decrease of efficiency.

Applying a holistic approach to assess the environmental impacts of CCS shows that the overall GHG emissions from CCS power stations will only be reduced in total by around 68 to 87 per cent, depending on the technology (up to 95 per cent only in exceptional cases of specific combinations of technologies and fuels). In addition, most capture processes would lead to a rise in non- $\mathrm{CO}_{2}$ emissions and other environmental factors due to the additional consumption of energy and chemicals used for $\mathrm{CO}_{2}$ capture. In contrary, most renewable energies show a much better environmental balance.

Finally, the availability of long-term, stable storage sites will be pivotal in determining the potential of CCS. If the total $\mathrm{CO}_{2}$ emissions caused by large point sources in Germany (power plants and industry) are considered (388 million tonnes per annum in 2007), then ultimately, due to the required penalty load, 454 million tonnes of $\mathrm{CO}_{2}$ would have to be captured annually. With the conservative estimate, these emissions can be stored for 12 years (basic value) or for 8 or 33 years (sensitivity values). If the "Realistic I" scenario is assumed, as calculated in section 2.2, a total of 1.2 billion tonnes of $\mathrm{CO}_{2}$ could be captured in the power plant sector by the year 2050, which, even under the assumption of the lowest estimate, could be stored within the geographic region of Germany. Only the effective capacity, however, was used as the basis in each comparison. The practical capacity, generally lower than the effective capacity, would yield lower utilisation periods.

However, our analysis of the studies and the adoption of a conservative estimate show that there remain major uncertainties concerning the estimation of storage potential, particularly with regard to saline aquifers. A further outcome is that the variation of individual parameters has a considerable impact on the results of the calculation. We should point out that not only existing, but also our own estimates, are based on rough data. It is important to state a lower 
estimate, however, in the sense of a minimum value, to give politicians and industry a basis for planning legislation and further investments.

\section{Conclusions and outlook}

Our integrated assessment of CCS leads to a unambiguous overall conclusion: there might not necessarily be a need to apply CCS in the German power plant sector. Even in case of ambitious climate protection targets, current energy policy priorities (expansion of renewable energies and combined heat and power plants as well as enhanced energy productivity) result in a limited demand for CCS. Although most of the results of the presented paper relate to Germany, similar conclusions might well be applicable for the rest of Europe, in view of several existing EU directives to expand renewable energies and increase energy efficiency (see, for example, the "EU climate and energy package", aiming for $20 \%$ of EU energy consumption to come from renewable resources, a reduction in EU greenhouse gas emissions of at least $20 \%$ below 1990 levels and a $20 \%$ reduction in primary energy use [31]).

However, recently, alternative applications are being increasingly considered - that is the capture of $\mathrm{CO}_{2}$ at industrial point sources and biomass based energy production (electricity, heat and fuels). It is in these fields of application, that we see a large demand for assessment studies to explore the potentials, limits and requirements for commercial use in Germany and abroad.

- $\mathrm{CO}_{2}$ emissions from industrial processes in Germany cumulate to 80 million tonnes [37] compared to a total of large-point emissions of 388 million tonnes in 2007. Unlike CCS in the power plant sector, the cut in $\mathrm{CO}_{2}$ emissions in the industrial context by 80 to 95 per cent seems not possible without this technology. Industry can only resort to using electricity and heat from renewable energies, where they are used directly (for example, in electricity powered steelworks), improve process efficiency or switch to alternative, more sustainable production processes. However, a significant share of emissions is processimmanent and cannot be avoided by applying measures such as renewable energies. At a global scale, the International 38 Agency projects that CCS at industrial emissions sources could contribute about 9 per cent to a 50 per cent emissions reduction (compared to the present level) by 2050 [39]. The United Nations Industrial Development Organization has recently published a Technology Roadmap on Carbon Capture and Storage in Industrial Applications [32].

- The application of CCS in biomass plants (power and heat production as well as fuels) is of interest because "negative" $\mathrm{CO}_{2}$ emissions can be achieved. By separating the $\mathrm{CO}_{2}$ absorbed by plants during growth, $\mathrm{CO}_{2}$ could not only be avoided, but extracted long-term from the atmosphere. This could become relevant if it proves to be impossible to achieve the set reduction targets in other areas [40]. Therefore, biomass-CCS could in terms of carbon mitigation represent a more effective option for using the limited German $\mathrm{CO}_{2}$ storage capacity than coal-fired power plants.

Nevertheless, globally, CCS at power plants might be an important climate protection technology: coal-consuming emerging economies with greatly increasing electricity demand such as China and India are increasingly moving centre stage in the debate. Besides assessment studies on the potential for CCS (in power plants, industrial sites and biomass applications) the potential for renewable energies and their usage should be investigated as well. Taking into consideration the results of our study, similar investigations on the development and the integration of both, CCS and renewable energies, into the individual energy system structures of such countries would be reasonable.

\section{References}

[1] BMWi (German Federal Ministry of Economics and Technology), 2010, "Energiedaten Zahlen und Fakten - Nationale und Internationale Entwicklung”, Berlin, Germany. 
[2] Viebahn P., Nitsch J., Fischedick M., Esken A., Schüwer D., Supersberger N., Zuberbühler U., Edenhofer O., 2007, "Comparison of carbon capture and storage with renewable energy technologies regarding structural, economic, and ecological aspects in Germany", Int. J. of Greenhouse Gas Control, Vol. 1, No. 1, pp. 121-133.

[3] European Commission, 2008, Communication from the Commission: 2020 by $2020-$ Europe's climate change opportunity, COM/2008/0030 final, http://eurlex.europa.eu/LexUriServ/LexUriServ.do?uri=CELEX:52008DC0030:EN:HTML:NOT

[4] WI (Wuppertal Institute for Climate, Environment and Energy), 2010, "RECCS Plus Comparison of Renewable Energy Technology with Carbon Dioxide Capture and Storage, Update and Expansion of the RECCS Study" on behalf of the German Federal Ministry for the Environment, Nature Conservation and Nuclear Safety, http://www.wupperinst.org/projekte/proj/index.html?projekt_id=286\&bid=155

[5] Gough C., Shackley S., Holloway S., Bentham M., Bulatov I., McLachlan C., Klemes J., Purdy R.W., Cockerill T., 2006, "An integrated assessment of carbon dioxide capture and storage in the UK", 8th International Conference on Greenhouse Gas Control Technologies, 2006, Trondheim, Norway.

[6] BMU (German Federal Ministry for the Environment, Nature Conservation and Nuclear Safety), 2008, "Lead Study 2008 - Further development of the 'Strategy to increase the use of renewable energies' within the context of the current climate protection goals of Germany and Europe", http://www.bmu.de/english/renewable_energy/downloads/doc/42726.php

[7] Bauer C., Heck T., Dones R., Mayer-Spohn O., Blesl M., 2008, "Final report on technical data, costs, and life cycle inventories of advanced fossil power generation systems" Deliverable 7.2., NEEDS (New Energy Externalities Developments for Sustainability). http://www.needsproject.org/

[8] Koornneef J., van Keulen T., Faaij A., Turkenburg W., 2008, "Life cycle assessment of a pulverized coal power plant with post-combustion capture, transport and storage of $\mathrm{CO}_{2}$ ", Int. J. of Greenhouse Gas Control, Vol. 2, No. 4, pp. 448-467.

[9] Schreiber A., Zapp P., Kuckshinrichs W., 2009, "Environmental assessment of German electricity generation from coal-fired power plants with amine-based carbon capture". Int J Life Cycle Assess, Vol. 14, No. 6, pp. 547-559.

[10] Pehnt M., Henkel J., 2009, "Life cycle assessment of carbon dioxide capture and storage from lignite power plants", Int J of Greenhouse Gas Control, Vol. 3, No. 1, pp. 49- 66.

[11] Vangkilde-Pedersen T., Vosgerau H., Willscher B., Neele F., van der Meer B., BossieCodreanu D., Wojcicki A., Nindre Y.-M. L., Kirk K., von Dalwigk I., Anthonsen K., 2009, "Capacity standards and site selection criteria", WP 4 Report D 26, EU Geocapacity, Denmark. [12] van der Straaten R., Elewaut E., Koelewijn D., Baily H., Holloway S., Barbier J., Lindeberg E., Möller H., Gaida K., 1996, "Inventory of the $\mathrm{CO}_{2}$ storage capacity of the European Union and Norway", In: Holloway S (ed.) Final report of the Joule II project No. CT92-0031: The Underground Disposal of Carbon Dioxide. British Geological Survey, Nottingham, pp. 16-115.

[13] Christensen N. P., Holloway S., 2004, "GESTCO - Geological Storage of $\mathrm{CO}_{2}$ from Combustion of Fossil Fuel (Summary Report)", European Commission, Brussels, Belgium.

[14] May F., Müller C., Bernstone C., 2005, "How much $\mathrm{CO}_{2}$ can be stored in deep saline aquifers in Germany?", VGB PowerTech, Vol. 85, No. 6, pp. 32-37.

[15] Knopf S., May F., Müller C., Gerling J.P., 2010, "Neuberechnung möglicher Kapazitäten zur $\mathrm{CO}_{2}$-Speicherung in tiefen Aquifer-Strukturen", Energiewirtschaftliche Tagesfragen, No. 4, pp. 76-80.

[16] BMU (German Federal Ministry for the Environment, Nature Conservation and Nuclear Safety), 2011, “Kabinett verabschiedet CCS-Gesetz", Press Release, 13 April 2011, Berlin, Germany.

[17] Scheffknecht, G., 2005, "Wege zum $\mathrm{CO}_{2}$-freien Kohlekraftwerk", 30. Sitzung DVVFachausschuss "Grundlagen und Anwendung”, 16 November 2005, Werne, Germany. 
[18] MIT (Massachsusetts Institute of Technology), 2007, “The future of coal - Options for a carbon-constrained world", An interdisciplinary MIT Study.

[19] ZEP (Zero Emissions Platform), 2008, "EU Demonstration Programme for $\mathrm{CO}_{2}$ Capture and Storage (CCS)". ZEP's Proposal. European Technology Platform for Zero Emission Fossil Fuel Power Plants.

[20] Greenpeace, 2008, "False Hope - Why carbon capture and storage won't save the climate", http://www.greenpeace.org/international/en/publications/reports/false-hope/

[21] Singh B., Strömman A.H., Hertwich E.G., 2011, "Comparative life cycle environmental assessment of CCS technologies”, Int. J. of Greenhouse Gas Control, Vol. 5, No. 4, pp. 911921.

[22] DONG Energy, 2008, "Final report on offshore wind technology", EU-NEEDS, http://www.needs-project.org/

[23] Frankl P., Menichetti E., Raugei M., 2008, "Final report on technical data, costs and life cycle inventories of PV applications", Deliverable No. 11.2-RS Ia, EU-NEEDS, http://www.needs-project.org/

[24] Viebahn P., Lechon Y., Trieb F., 2011, "The potential role of concentrated solar power (CSP) in Africa and Europe - A dynamic assessment of technology development, cost development and life cycle inventories until 2050", Energy Policy, Vol. 39, No. 8, pp. 44204430.

[25] van der Meer L.G.H., Yavuz F., 2009, " $\mathrm{CO}_{2}$ storage capacity calculations for the Dutch subsurface”, Energy Procedia, Vol. 1, No. 1, pp. 2615-2622.

[26] IEA GHG, 2009, " $\mathrm{CO}_{2}$ storage in depleted gas fields", IEA Greenhouse Gas R\&D Programme, Technical study No. 2009/01.

[27] Ehlig-Economides C., Economides M.J., 2010, "Sequestering carbon dioxide in a closed underground volume", J of Petroleum Science and Engineering, Vol. 70, pp 123-130.

[28] Holloway S., Vincent C., Bentham M., Kirk K., 2006, "Top-down and bottom-up estimates of $\mathrm{CO}_{2}$ storage capacity in the UK sector of the southern North Sea basin", Environmental Geosciences, Vol. 13, No. 2, pp. 71-84.

[29] May F., 2009, "Aquifer storage - An option for emission reduction in Germany", Presentation at the IFP conference on Deep Saline Aquifers for Geological Storage of $\mathrm{CO}_{2}$ and Energy, Paris, France.

[30] Gerling J. P., 2008, "Geologische $\mathrm{CO}_{2}$-Speicherung als Beitrag zur nachhaltigen Energieversorgung", Bergbau, No. 10, pp. 472-475.

[31] Sims R.E.H., Rogner H.-H., Gregory K., 2003, "Carbon emission and mitigation cost comparisons between fossil fuel, nuclear and renewable energy resources for electricity generation", Energy Policy, Vol. 31, No. 13, pp. 1315-1326.

[32] McKinsey\&Company, 2009, "Kosten und Potenziale der Vermeidung von Treibhausgasemissionen in Deutschland", Studie im Auftrag von "BDI initiative - Wirtschaft für Klimaschutz",

http://www.mckinsey.com/Client_Service/Sustainability/Latest thinking/Costcurves

[33] McKinsey\&Company, 2009, "Pathways to a Low-Carbon Economy. Version 2 of the Global Greenhouse Gas Abatement Cost Curve", www.worldwildlife.org/climate/WWFBinaryitem11334.pdf

[34] McKinsey\&Company, 2008, "Carbon Capture \& Storage: Assessing the Economics", w34ww.assets.wwf.ch/downloads/mckinsey2008.pdf

[35] Ludig S., Haller M., Bauer N., 2011, "Tackling long-term climate change together: the case of flexible CCS and fluctuating renewable energy", Energy Procedia 4(2011), 2580-2587.

[36] Spliethoff H, 2011, "Advanced Power Plants - Coal Fired Steam Power Plant". Proceedings of $2^{\text {nd }}$ Int. Conf. on Energy Process Engineering - Efficient Carbon Capture for Coal Power Plants. 20-22 June 2011 Frankfurt.

[37] Öko-Institut, 2009, "Regulierung von $\mathrm{CO}_{2}$-Abscheidung und -Ablagerung - Der Entwurf für das Kohlendioxid-Speicherungsgesetz $(\mathrm{KSpG})$ ". Stellungnahme zum Entwurf für das 
Kohlendioxid-Speicherungsgesetz (KSpG) zur Anhörung des Ausschusses für Umwelt, Naturschutz und Reaktorsicherheit des 16. Deutschen Bundestages am 25. Mai 2009.

[38] IEA (International Energy Agency), 2009, "Technology roadmap - Carbon capture and storage", Paris, France.

[39] UNIDO (United Nations Industrial Development Organization), 2011, "Technology Roadmap - Carbon Capture and Storage in Industrial Applications", www.iea.org/papers/roadmaps/ccs_industry.pdf

[40] Azar C., Lindgren K., Obersteiner M., Riahi K., van Vuuren D. P., Michel K., den Elzen G. J., Möllersten K., Larson E. D., 2010, "The feasibility of low $\mathrm{CO}_{2}$ concentration targets and the role of bio-energy with carbon capture and storage (BECCS)", Climate Change Vol. 100, No. 1, pp. 195-202.

\section{Acknowledgements}

This paper is based on the report RECCS Plus, which was financially supported by the German Federal Ministry for the Environment, Nature Conservation and Nuclear Safety. We would like to thank the reviewers for their comments and suggestions. Furthermore, we thank our colleagues Andrea Esken, Manfred Fischedick, Jochen Luhmann and Katja Pietzner as well as our subcontractor Joachim Nitsch for their contributions to RECCS Plus, which we used for this article. 